\title{
Phloem Water Transport Maintains Stem Growth in a Drought-stressed Crop Cactus (Hylocereus undatus)
}

\author{
Avinoam Nerd and Peter M. Neumann1 \\ Plant Physiology Laboratory, Department of Environmental, Water and Agricultural Engineering, Faculty \\ of Civil and Environmental Engineering, Technion Israel Institute of Technology, Haifa 32000, Israel
}

\begin{abstract}
AdDitional InDEX words. pitaya, deficit irrigation, succulent stem, water potential, extrafloral nectar, girdle, hydraulic conductivity

Abstract. Hylocereus undatus [(Haworth) Britton and Rose] is a vine cactus from central America that has been established as a new fruit crop (pitaya) in many tropical and subtropical countries. In order to develop improved irrigation practices, the relationships between water parameters and growth were studied in rooted stem cuttings growing in pots with sandy soil under well-watered and drought-stressed conditions, in a controlled environment. Soil water potential rapidly decreased from - 0.02 to -1.5 MPa during the first 5 days of drought. However, growth of new stems emerging from the succulent mature stems only decreased significantly after 3 weeks of drought. After 3 weeks of drought, the water content of growing stems decreased by $2 \%(P<0.05)$ and their water potentials by $0.05 \mathrm{MPa}(P>0.05)$, as compared with the irrigated controls. At the same time, water content in drought-treated mature stems decreased by $4 \%$ $(P<0.05)$ and water potentials by $0.25 \mathrm{MPa}(P<0.05)$. Several lines of evidence indicated that active phloem supply of assimilates and associated water reserves from mature stems was the mechanism that allowed developing stems of $H$. undatus to maintain growth under well-watered and drought conditions: 1) Girdling the phloem of growing stems rapidly inhibited stem elongation. 2) Secretion of sucrose-containing nectar by growing stems was maintained during drought. 3) The water potential gradient was in the wrong direction for xylem transport from mature to young growing stems and axial hydraulic conductivity in young stems was either zero or comparatively low.
\end{abstract}

Hylocereus undatus is a shade-tolerant vine cactus from tropical forests of central America. It produces medium-large scaly fruit of the red pitaya type on succulent and slender leafless stems that act as the photosynthetic organs of the plant (Nerd et al., 2002a; Nobel and De La Barrera, 2002). The plant has been developed recently as a fruit crop in many subtropical and tropical countries over the world (Nerd et al., 2002a; Nobel and De la Barrera, 2002). Cultivation of $H$. undatus in dry subtropical regions as opposed to humid regions requires irrigation but the plants in drier regions are almost free from diseases and most of the fruit is marketable (Nerd et al., 2002a, 2002b).

Little is known about the water requirements of $H$. undatus or related vine cactus crops such as $H$. polyrhizus or Selenicereus megalanthus (Nerd et al., 2002a). In Israel, vine cactus crops are drip irrigated year round (except in rainy periods) to keep the soil permanently moist (Nerd et al., 2002b). Flowering and fruit growth of $H$. undatus in Israel occurs primarily in the mild autumn and is depressed in the hot summer months. The green and succulent mature stems of $H$. undatus, from which the young stems grow out, store large amounts of water and have a CAM photosynthetic pathway (Nobel and De la Barrerra, 2002). In contrast to flower and fruit growth, stem growth is most vigorous in the summer. Indeed, the orchards then manifest excessive stem growth and have to be pruned frequently (Nerd et al., 2002b). A common first response of plants to water stress is the inhibition of shoot growth (Bradford and Hsaio, 1982; Chazen and Neumann 1994). A deficit irrigation approach (Johnson and Handley, 2000)

Received for publication 30 June 2003. Accepted for publication 20 Nov. 2003. The authors thank Ido Seginer and Benjamin Zur for their careful reading of the early version of this paper.

${ }^{1}$ To whom reprint request should be addressed; e-mail:agpetern@tx.technion. ac.il could therefore be considered as a management technique for reducing excessive vegetative growth in $H$. undatus during the hot summer. The stem-growth responses of $H$. undatus to drought do not appear to have been studied and may differ from those of more conventional $\mathrm{C}_{3}$ or $\mathrm{C}_{4}$ crops (Nobel 1991). Investigations of the effects of drought on stem growth and its physiological aspects may contribute to the development of an optimal irrigation regime for $H$. undatus.

The specific aims of the present work were to: 1) quantify effects of drought on growth and on water relations in the mature and growing stems of potted $H$. undatus plants and 2) investigate possible water transport mechanisms involved in the maintenance of stem growth.

\section{Materials and Methods}

Plant material. Rooted cuttings of Hylocereus undatus cultivated in Israel (Nerd et al., 2002b), were grown in a shaded glasshouse in 1.5-L pots filled with sandy soil obtained from the southern coast of Israel (Besor region). When total length of the mature stem segments (succulent, deep-green, three-ribbed internodes) reached $60-70 \mathrm{~cm}$, the plants were placed in a growth room with a temperature of $27 \pm 1{ }^{\circ} \mathrm{C}, 12$-h photoperiod, photosynthetic active radiation of $150 \mu \mathrm{mol} \cdot \mathrm{m}^{-2} \cdot \mathrm{s}^{-1}$, and light/dark relative humidities of $30 \%$ and $70 \%$. Plants were irrigated at 2-d intervals until drainage with water containing $20 \mathrm{~N}-9 \mathrm{P}-17 \mathrm{~K}$ fertilizer enriched with microelements (Deshen-Kol, Haifa Chemicals, Israel) at a concentration of $200 \mathrm{mg} \cdot \mathrm{L}^{-1}$.

IRRIGATION TREATMENTS. After 3-4 weeks in the growth room, plants with two to three newly initiated young stems, $0.4 \mathrm{~cm}$ to $1.1 \mathrm{~cm}$ in length, were selected for study. Two treatments were applied: 1) Drought treatment: irrigation was withheld for $27 \mathrm{~d}$. 2) Well-watered control treatment: irrigation was as usual but 
without fertilizer. Results are for a complete random design with nine plants per treatment.

SOIL WATER AND PLANT WATER PARAMETERS. Soil sampled at mid depth of the pot was oven-dried $\left(105^{\circ} \mathrm{C}\right)$ to determine soil water content. Stem water content, water potential $(\Psi)$, and osmotic potential $(\pi)$ were measured in tissue sampled at the beginning of the light period with a cork-borer (10 $\mathrm{mm}$ in diameter) at just above midlength of stem segments. Water content of stems was determined by drying at $70{ }^{\circ} \mathrm{C} . \Psi$ (fresh tissue) and $\pi$ (frozen tissue) were determined by thermocouple psychrometry using 0.5-mLchambers (Series 76; J.D. Merrill,Logan, Utah) connected to a Wescor micro-voltmeter (Chazen and Neumann, 1994). Estimates of bulk turgor pressure were obtained by subtracting osmotic potential from water potential.

Stem Growth. Long-term elongation of stems initiated at the beginning of the irrigation study was measured with a ruler at 4-5 dintervals for 4 weeks $(n=5)$. The stems were then harvested and oven-dried $\left(70{ }^{\circ} \mathrm{C}\right)$ for dry weight determination. Instantaneous length changes were measured by attaching stem tips vertically mounted on intact plants to a linear variable differential transformer (LVDT; Instruments and Control, Haifa) using a chart recorder for the output (Neumann, 1993). A relationship between dry weight and length was determined for growing stems that were harvested from watered plants at different stages of development. A second-order polynomial was fitted to the relationship between stem dry weight $(\mathrm{Y}, \mathrm{g})$ and stem length $(\mathrm{x}, \mathrm{cm})$ where $\mathrm{Y}=0.04192$ $+0.0099 \mathrm{X}+0.0032 \mathrm{X}^{2}\left(R^{2}=0.924\right)$.

EXTRAFLORAL NECTAR. Drops of nectar appeared on the back of areoles (located along the crest of stem ribs) in elongating stems. Analysis of sugars in nectar collected from watered plants showed that sucrose composed from $65 \%$ to $69 \%$ of nectar dry weight (unpublished data). Nectar newly produced by stems of droughted and irrigated plants $(n=3)$ during the third week was collected with forceps, air-dried and weighed.

GiRDLING. Watered plants with two adjacent stems of similar length growing out of the basal mature stem were selected for the girdling study. The nonfleshy cylindrical stalk at the base of the growing stems was rapidly girdled with a razor and the wound left by removal of a 1-mm strip of cortex was immediately covered with petroleum jelly to prevent water loss. The process was completed within $1 \mathrm{~min}$. Daily elongation of growing stems was assayed for $2 \mathrm{~d}$ after girdling $(\mathrm{n}=5)$. In other experiments, instantaneous growth responses of girdled stems and of nongirdled controls were continuously measured by LVDT.

STEM HYDRAulic CONDUCTIVITY. Measurements of pressure induced flow through water conductive tissues in the stem were made in watered plants with segments, $2.5 \mathrm{~cm}$ in length, cut from the base of young growing stems at 10 or $20 \mathrm{~d}$ after initiation or from underlying mature stems segments $(\mathrm{n}=5)$. After exposing $3 \mathrm{~mm}$ of the central cylinder containing the xylem from the top and bottom of the segment, the top end was tightly connected to water filled tubing and a controlled pressure of $150 \mathrm{kPa}$ was applied. A graduated pipette was attached to the lower end of the segment and used to measure the flow rate of water through the segment. A0.1-mL pipette was used for young stems and a 1.0-mL pipette for mature stems. These allowed volume changes of $1 \mu \mathrm{L}$ and $10 \mu \mathrm{L}$, respectively, to be accurately determined. Flow was allowed to equilibrate for $5 \mathrm{~min}$ before making measurements. Axial hydraulic conductivity of stems, $\mathrm{k}_{\mathrm{h}}\left(\mu \mathrm{L} \cdot \mathrm{s}^{-1} \cdot \mathrm{MPa}^{-1} \cdot \mathrm{m}^{-1}\right)$ was calculated from $\mathrm{k}_{\mathrm{h}}=\mathrm{qx} \cdot \Delta \mathrm{P}^{-1}$ where $\mathrm{x}(\mathrm{m})$ is the stem segment length, $\mathrm{P}\left(\mathrm{MPa}^{-1}\right)$ the applied pressure difference, and $\mathrm{q}\left(\mu \mathrm{L} \cdot \mathrm{s}^{-1}\right)$ the flow rate (Lovisolo and Schubert, 1998).
STATISTICS. Standard errors and LSDS were calculated for the comparisons between means.

\section{Results}

SoIL WATER CONTENT AND STEM GROWTH. Soil water content decreased rapidly after withholding irrigation (Fig. 1, insert). Volumetric water content was $17 \%$ on the first day after the cessation of irrigation and decreased to $7.2 \%$ on the fourth day. These values were equivalent to soil water potentials of -0.02 and $-1.50 \mathrm{MPa}$, respectively, for the investigated soil (E. Raveh, Gilat experimental station, Israel; personal communication). The soil water potential after $4 \mathrm{~d}$ was far more negative than water potentials measured in growing and mature stems (see below). Soil water was therefore presumed unavailable to the plants after day 4. Stem elongation rates for control and irrigated plants are shown in Fig. 1. The rapid drying of the soil did not cause significant reductions in stem length, as compared with watered controls, during the first $17 \mathrm{~d}$ of drought treatment. Significant reductions were measured at and after $20 \mathrm{~d}$. At the end of the study period, the length of new stems was $24 \%$ lower $(P<0.05)$ in droughted plants than in the control plants $(19.0 \pm 0.6 \mathrm{~cm}$ compared to 24.9 $\pm 0.9 \mathrm{~cm})$ and dry weights of new stems in droughted plants were $13 \%$ lower $(P>0.05)$ than in control plants $(2.0 \pm 0.16 \mathrm{~g} \mathrm{com}-$ pared to $2.31 \pm 0.16 \mathrm{~g}$ ). Overall, the young stems of droughted plants were able to maintain growth at relatively high rates for four weeks, despite the rapid drying of the soil.

Water Relations. Figure 2 shows water contents in growing and mature stem segments measured as percentages of fresh weight. Water content in the growing stems of irrigated plants decreased slightly between day 15 and day 27 . The water content of the droughted stems was $2.5 \%$ lower. The same drought treatment reduced water content in mature stems by $8.1 \%$ after $27 \mathrm{~d}$. Note that the onset of drought induced decreases in water content of the mature stems in Fig. 2 preceded the onset of decreases in the water content of the growing stems.

Stem water potentials measured in the mature stems at 3 weeks after the beginning of the study were more negative than in the growing stems (Table 1). Paradoxically, such water potential gradients would favor water movement from the young growing stems to the mature stems. Table 1 also shows that drought treat-

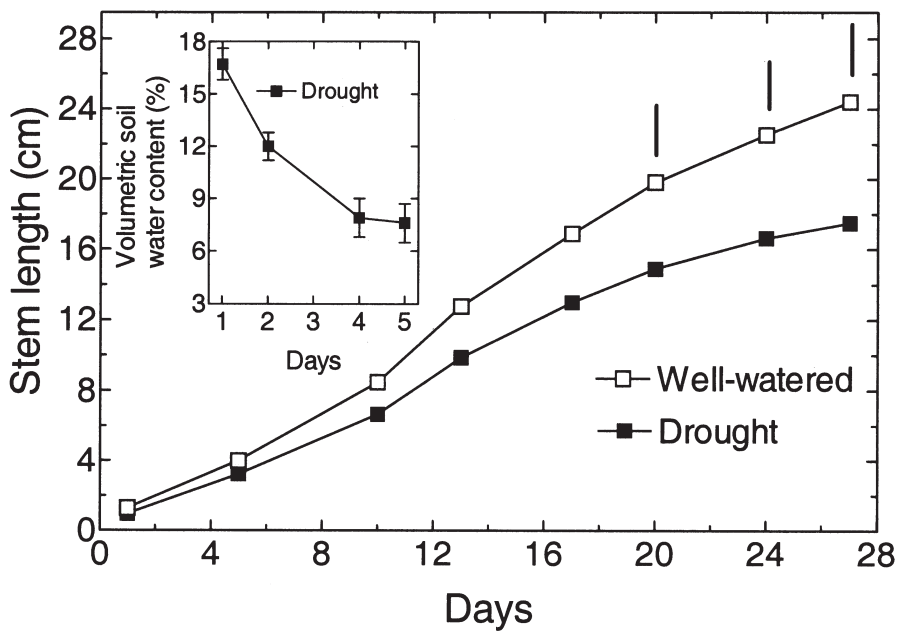

Fig. 1. Time courses for increase in stem length of droughted and well-watered $H$. undatus. Data points are averages for five growing stems. Vertical bars indicate LSD between treatments at $P=0.05$. 


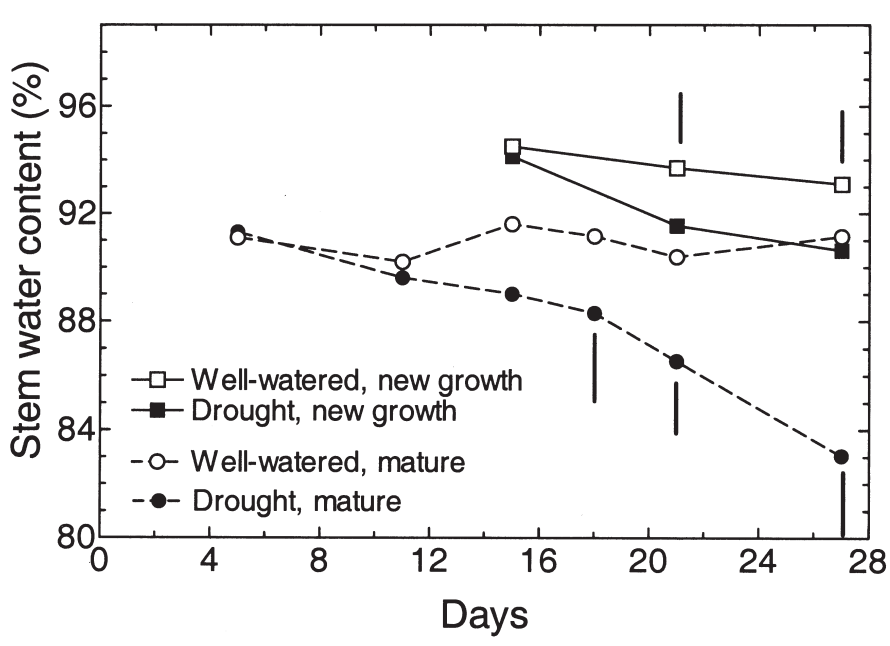

Fig. 2. Time courses for water content (\% fresh weight) changes in stem tissue of droughted and well-watered $H$. undatus. Vertical bars indicate LSD between treatments at $P=0.05$ for growing stems (square symbols) and mature stems (circular symbols-dashed lines).

Table 1. Effects of 3 weeks of drought on water potential $(\Psi)$, osmotic potential $(\pi)$, and estimated bulk turgor pressure $(\mathrm{P})$ in young growing stems or mature stems of $H$. undatus. Data are means $\pm \mathrm{SE}, \mathrm{n}=5$.

\begin{tabular}{llccc}
\hline Stem type & Treatment & $\Psi(\mathrm{MPa})$ & $\pi(\mathrm{MPa})$ & $\mathrm{P}(\mathrm{MPa})$ \\
\hline Growing & Well-watered & $-0.38 \pm 0.02$ & $-0.54 \pm 0.05$ & $0.29 \pm 0.04$ \\
& Drought & $-0.43 \pm 0.05$ & $-0.61 \pm 0.04$ & $0.21 \pm 0.05$ \\
LSD $_{0.05}$ & & $\mathrm{NS}$ & $\mathrm{NS}$ & $\mathrm{NS}$ \\
Mature & Well-watered & $-0.55 \pm 0.01$ & $-0.64 \pm 0.01$ & $0.18 \pm 0.03$ \\
& Drought & $-0.80 \pm 0.03$ & $-0.84 \pm 0.02$ & $0.04 \pm 0.02$ \\
LSD $_{0.05}$ & & 0.11 & 0.08 & 0.11 \\
\hline
\end{tabular}

ment only induced significant $(P<0.05)$ lowering of stem water potential and osmotic potential (as compared with well watered controls) in mature stem segments. These findings are consistent with the observation that water content in mature stems decreased more than in young stems. Turgor pressure is required for cell expansion during growth and interestingly, the calculated bulk turgor pressures were consistently higher in the growing stems than in the mature stems. Moreover, turgor in mature stems was significantly decreased by drought treatment $(P<0.05)$, whereas turgor in growing stems was not.

EFFECT OF GIRDLING ON STEM ELONGATION. Growth in young stems requires an ongoing supply of water and measured water potential gradients did not appear to favor xylem water flow from soil to mature stem to growing stem. The possible involvement of active phloem transport of water (together with dissolved photo-assimilates) from mature to growing stems was therefore investigated by measuring the effect of phloem disruption, by girdling, on stem growth. Girdling consistently reduced the elongation rates of young stems as compared with adjacent control stems growing out of the same mature stem (Fig. 3).

In addition, short-term changes in the tip position of growing stems were continuously followed using an LVDT set up. Although slow growth was maintained during the dark period, $\approx 90 \%$ of the daily length increase in nongirdled (control) stems occurred during the 12-h light period. This predominance of light-time elongation also occurred in a humid chamber (data not shown). Phloem girdling during the light period immediately slowed down stem elongation and elongation was more inhibited at night. Reduced elongation (compared with nongirdled controls)

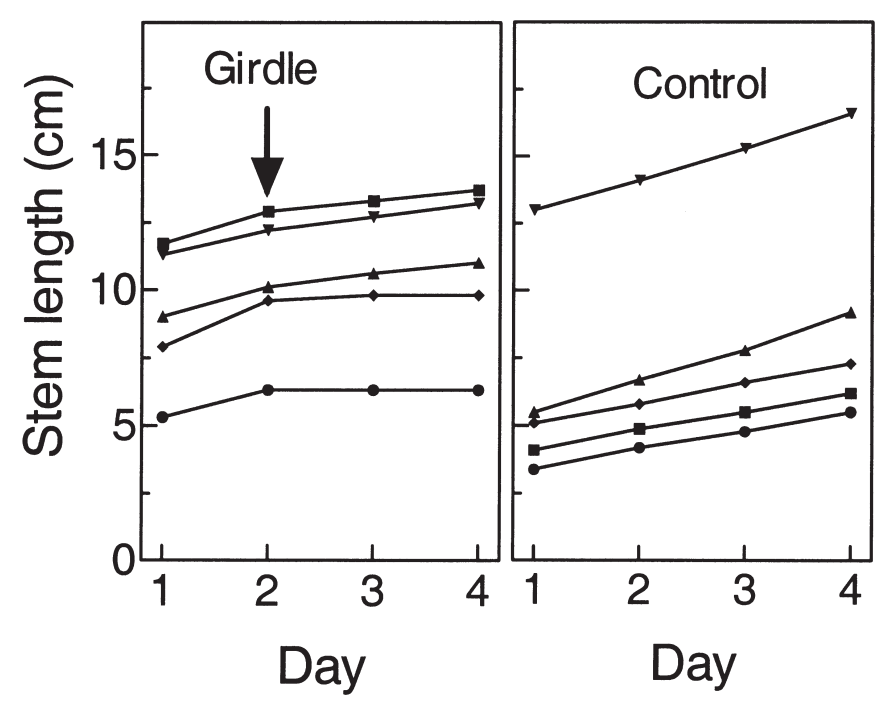

Fig. 3. Effects of girdling on daily stem elongation of $H$. undatus. The elongation of adjacent stems (same symbols) growing out of an underlying mature stem was assayed with a ruler.

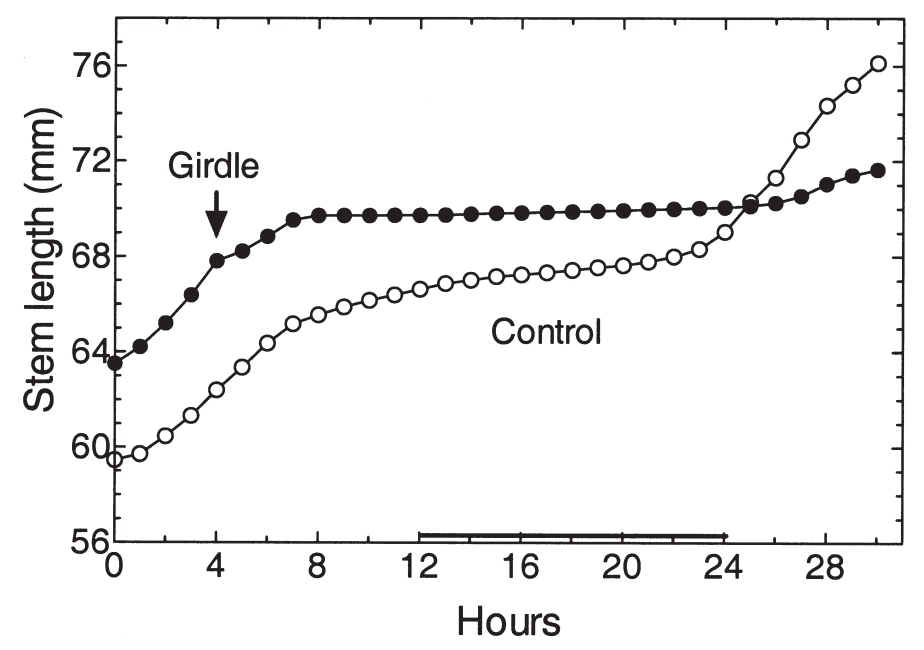

Fig. 4. Instantaneous effect of girdling on stem elongation in $H$. undatus. Continuous measurements were made on a girdled stem of $7.0 \mathrm{~cm}$ length for $30 \mathrm{~h}$. Elongation of the adjacent control stem was subsequently assayed. The horizontal bar on the $\mathrm{x}$-axis indicates the dark period. The data are representative of three separate studies.

was resumed in the following light period (Fig. 4). Wounding the stem by similar but superficial girdling caused only transient effects that were reversed within minutes (data not shown). Thus, phloem transport into young stems of $H$. undatus appeared to be involved in the maintenance of stem elongation.

NeCtar SECRETion. Drops of nectar emerged on the back of areoles (located along the ribs of stems) during elongation of young stems in plants of both control and drought treatments. Measurements of nectar yield during the third week of the study showed that drought decreased $(P<0.05)$ but did not prevent nectar secretion; dry weight of nectar collected from droughted plants was $6.3 \pm 0.11 \mathrm{mg} / \mathrm{stem}$ and from control plants, $15.3 \pm$ $0.13 \mathrm{mg} / \mathrm{stem}$. The occurrence of sugar secretion in growing stems of droughted plants suggested that phloem transport was maintained and that sugar availability was not overly limited under drought conditions. 
Axial hydRaulic CONDUCTIVITy. Long distance xylem water transport is dependent on water potential gradients between source and destination and the conductivity of the xylem pathway connecting them. The fact that water potentials in the mature stems were found to be more negative than in growing stems suggested that essential water supplies, rather than being imported into young growing stems via the xylem, might be exported. In order to further investigate this possibility, the axial hydraulic conductivity of water conducting tissues at the base of growing stems was assayed. Axial hydraulic conductivity was zero in young stems at $10 \mathrm{~d}$ (Fig. 5) and was not increased by raising the pressure drop from 0.15 to $0.45 \mathrm{kPa}$ (not shown). However, axial conductivity did increase with developmental age. Thus, very low conductivity values were measured in 20 -d stems and mature stems were very conductive. The order of magnitude differences in conductivities of 20-d and mature stems were not simply a function of differences in the diameters of the central water conducting tissues in the stems; these were $9.8 \pm 1.7 \mathrm{~mm}^{2}$ in 20-d-old stems and $23.8 \pm 4.7 \mathrm{~mm}^{2}$ in mature stems $(\mathrm{n}=5)$. In all events, the conductivity of the water pathway leading from the young to the mature stem was apparently inhibited during early stem development.

\section{Discussion}

Reductions in shoot growth are among the earliest observed responses to water deficit in many plants (Bradford and Hsiao, 1982; Chazen and Neumann, 1994). However, the present work shows that young stems of $H$. undatus that were initiated at the beginning of the irrigation study, continued to elongate and to accumulate substantial amounts of dry matter during 4 weeks of progressive drought. For most of this period, soil water was not available to the plants, i.e., water content of the soil was very low and corresponded to water potentials more negative than those measured in the plants. The drought treatment mainly affected the water status of the mature stems. Their water content and water potentials had decreased markedly 3 weeks after the cessation of irrigation. The same drought treatment had only minor effects on the water status of growing stems. Thus, a specific avoidance of water deficit in growing stems might explain their remarkable ability to maintain growth despite the nonavailability of soil water.

The water potential gradients found to exist between young and mature stems after 3 weeks of control or drought-treatment would be expected to favor xylem water transport out of, rather than into young stems. It is therefore rather unlikely that the growth of young stems depended on water import via the xylem. Moreover, the zero to low axial hydraulic conductivities of young stems suggested a further limitation to water import. Indeed, a high resistance to xylem water transport could serve to limit the undesirable export of essential water from young stems to the mature stems with more negative water potentials, at least until further development of the young stems turns them from sinks to potential sources of water. The stems of $H$. undatus are rich in mucilages (unpublished data) and the xylem of young stems might be blocked with mucilages or, alternatively, by slow maturation of the developing xylem cells (cf. Neumann, 1987).

An alternative possibility is that stem growth in H.undatus was primarily dependent on active phloem transport of water from mature to developing stems. It is well known that developing fruits can be dependent on phloem supplies of water for their growth

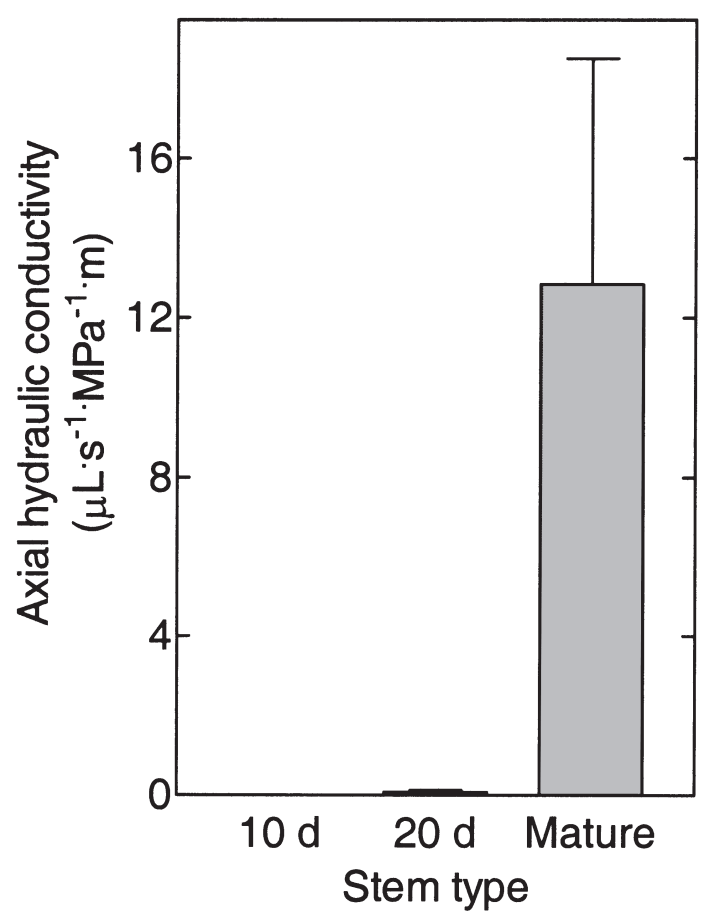

Fig. 5.Axial hydraulic conductivities measured in basal segments excised from young growing stems ( 10 or $20 \mathrm{~d}$ old) and segments excised from the underlying mature stems of watered $H$. undatus plants. Segment length was $2.5 \mathrm{~cm}$. Data are means $\pm \mathrm{SE}, \mathrm{n}=5$.

but dependence of stem growth, and especially stem growth during drought, on phloem supply of water does not appear to have been reported. Nobel et al. (1994) showed that developing fruits of the cactus pear Opuntia ficus-indica under well-watered conditions were able to import water through the phloem and against the water potential gradients between the growing fruit and supporting stem segments. Under drying conditions, fruit growth in O.ficus-indica was maintained until the onset of severe water deficit (50\% water loss) in the water-storing stem segments upon which the fruits developed (Nerd and Nobel, 2001). Finally, Wang et al. $(1997,1998)$ indicated the involvement of phloem water transport in stem growth of well-watered $O$. ficus-indica. A low percentage of assimilates $(6 \%)$ and correspondingly high percentage of water were found in the phloem sap. This supported the notion that the phloem could act as an effective supplier of water to the developing stems.

Assimilate (and water) content in phloem sap of young stems of watered $H$. undatus plants at the midtime of our study can be estimated by assuming that import via the phloem provided all the assimilate needed for dry weight increase, together with the water needed for stem growth and transpiration. The rate of stem dry weight increase for $15-\mathrm{cm}$ stems $(0.124 \mathrm{~g} \mathrm{DW} / \mathrm{stem} /$ day $)$ plus estimated rate of loss of dry matter through respiration $(0.031 \mathrm{mg}$ glucose/stem/day, after Chapotin et al., 2003) were divided by transpirational water loss $(1.0 \mathrm{~g} / \mathrm{stem} /$ day $)$ plus water accumulation for growth $(1.94 \mathrm{~g} / \mathrm{stem} /$ day $)$. Water loss by transpiration was measured gravimetrically in exposed growing stems attached to small segments of mature stem sealed in petroleum jelly and foil (data not shown). Water accumulation by growth was estimated on the basis that $94 \%$ of fresh weight was water in growing stems. Using this approach, the calculated value for assimilate concentration in phloem sap of $H$. undatus was $5.3 \%$ (i.e., $94.7 \%$ 
water). The similarity to phloem sap in $O$. ficus-indica supports the idea that phloem could also be a major provider of water for the growing stems of $H$. undatus.

The inhibition of elongation by girdling, as shown in Figs. 3 and 4 , confirmed the importance for growth of active phloem sap transport into young stems of $H$. undatus. The changing pattern of light/dark elongation rates in these stems may be controlled by a circadian system affected by light (Sweeney, 1987). Girdling presumably interrupted the phloem supply of both water and assimilates to the developing stems. Shortages of either could negatively affect growth. However, the rapidity of the reduction in stem elongation rate induced immediately after girdling, suggested a hydraulic effect (Bradford and Hsiao, 1982; Chazen and Neumann, 1994). Thus, water supply via the phloem appears to be of primary importance for the maintenance of stem growth in $H$. undatus. The relatively small inhibition of stem growth that nevertheless occurred in drought-treated $H$. undatus may have been related to a drought-induced reduction in the availability of assimilates. Thus, net $\mathrm{CO}_{2}$ uptake and assimilate production in mature $H$. undatus is known to decrease rapidly when roots confront dry soil (Nobel and De La Barerra, 2002). Allocation of assimilates for nectar secretion in $H$. undatus was much smaller than for growth. Daily nectar secretion in control plants was 0.0015 $\mathrm{g}$ DW/stem vs. daily dry weight increases of $0.1240 \mathrm{~g} \mathrm{DW} / \mathrm{stem}$ (from a fitted relationship between stem dry weight and stem length) during the same period. However, the observation that nectar secretion was reduced during the drought treatment, supports the notion that assimilate availability was generally reduced. Secretion of extra-floral nectar is very common in flowering plants including cacti and can benefit the plants by attracting ants that reduce herbivory (De La Fuente and Marquis, 1999; Engel et al., 2001; Ruffner and Clark 1986).

Why do $H$. undatus plants invest valuable resources in maintaining stem elongation while undergoing severe drought? Hylocereus undatus is a semi-epiphytic shrub from tropical forests (Benzing, 1990; Nobel and De La Barrera, 2002) with roots produced in the ground and in microsites (as adventitious roots) in the tree canopies on which the plants climb. Conceivably, plant competition for water and light in tropical tree canopies is a major determinant of success for this creeping vine cactus; maintenance of upward stem growth, even in dry soil, could therefore be advantageous. The need to maintain stem growth suggests that growth inhibition by hormonal, hydraulic or electrical signals from the drying roots, as often found in more conventional plants (Davies and Zhang, 1991), will be absent in $H$. undatus.

In conclusion, several lines of evidence indicate that phloem transport of assimilates and associated water reserves from mature stems, is the mechanism which allows developing stems of $H$. undatus to maintain stem growth under well-watered conditions and, in a remarkably effective manner, under severe drought: 1 ) Girdling the phloem at the base of growing stems rapidly inhibited their elongation. 2) Secretion of sucrose-containing nectar by growing stems continued during drought. 3) The water potential gradient was in the wrong direction for xylem water transport from mature to growing stems and the axial hydraulic conductivity in growing stems was zero or comparatively low. The ability to utilize water stored in mature stems for new growth, even under dry soil conditions, is a factor to be considered in scheduling irrigation regimes for $H$. undatus and in strategies for limiting excessive stem growth in hot summer months by limiting irrigation.

\section{Literature Cited}

Benzing, D.H. 1990. Vascular epiphytes. Cambridge Univ. Press, Cambridge.

Bradford, K.J. and T.C. Hsiao. 1982. Physiological responses to moderate water stress, p. 263-324. In: O.L. Lange, P.S. Nobel, C.B. Osmond, and H. Zieler (eds.). Physiological plant ecology. Springer, New York.

Chapotin, C.M., N.M. Holbrook, S.R. Morse, and M.V. Guitierrez. 2003. Water relations of tropical dry forest flowers: Pathway for water entry and the role of extracellular polysaccharides. Plant Cell Environ. 26:623-630.

Chazen, O. and P.M. Neumann. 1994. Hydraulic signals from the roots and rapid cell wall hardening in growing maize leaves, are primary responses to PEG induced water deficits. Plant Physiol. 104:1385-1392

Davies, W.J. and J. Zhang. 1991. Root signals and the regulation of growth and development of plant in drying soil. Annu. Rev. Plant Physiol. Plant Mol. Biol. 42:55-76.

De la Fuente, M.S. and R.J. Marquis. 1999. The role of ant-tended extrafloral nectaries in the protection and benefit of a Neotropical rainforest tree. Oecologia 118:192-202.

Engel, V., M.K. Fischer, and F.L. Wackers. 2001. Interaction between extrafloral nectaries, aphids and ants: Are their competition effects between plant and homopteran sugar sources. Oecologia 127:577-584.

Johnson, R.S. and D.F. Handley. 2000. Using water stress to control vegetative growth productivity of temperate fruit trees. HortScience 35:1048-1050.

Lovisolo, L. and A. Schubert 1998. Effect of water stress on vessel size and xylem hydraulic conductivity in Vitis vinifera L. J. Expt. Bot. 49:693-700.

Luo, Y. and P.S. Nobel. 1993. Growth characteristics of newly initiated cladodes of $O$. ficus-indica as affected by shading, drought and elevated $\mathrm{CO}_{2}$. Physiol. Plant. 87:467-474.

Nerd, A. and P.S. Nobel. 2000. Water relations during ripening for fruit of well-watered versus water-stressed Opuntia ficus-indica. J. Amer. Soc. Hort. Sci. 125:653-657.

Nerd, A., Y. Sitrit, R.A. Kaushik, and Y. Mizrahi. 2002b. High summer temperatures inhibit flowering in vine pitaya crops (Hylocereus spp.). Scient. Hort. 96:343-350.

Nerd, A., N. Tel-Zur, and Y. Mizrahi. 2002a. Fruit of vine and columnar cacti, p. 185-197. In: P.S. Nobel (ed.). Cacti: Biology and uses. Univ. of California, Berkeley.

Neumann, P.M. 1987. Sequential leaf senescence and correlatively controlled increase in xylem flow resistance. Plant Physiol. 83:941-944.

Neumann, P.M. 1993. Rapid and reversible modification of extension capacity of cell wall in elongating maize leaf tissues responding to root addition and removal of NaCl. Plant Cell Environ. 16:1107-1114.

Nobel, P.S. 1991. Achievable productivities of certain CAM plants: Basis for high value compared with $\mathrm{C}_{3}$ and $\mathrm{C}_{4}$ plants. New Phytol. 119: 183-205

Nobel, P.S., J.L. Andrade, W. Ning, and G.B. North. 1994. Water potential for developing cladodes and fruit of a succulent plant, including xylem-versus-phloem implications for water movement. J. Expt. Bot. 281:1801-1807.

Nobel, P.S. and E. De La Barrera. 2002. Stem water relations and net $\mathrm{CO}_{2}$ uptake for a hemiepiphytic cactus during short-term drought. Environ. Expt. Bot. 48:129-137.

Rufner, G.A. and W.D. Clark 1986. Extrafloral nectar of Ferocactus acantodes (Cactaceae); consumption and its importance to ants. Amer. J. Bot. 73:185-189.

Sweeney, B.M. 1987. Rhythmic phenomena in plants. Academic, San Diego.

Wang, N., H. Zhang, and P.S. Nobel. 1997. Phloem-xylem water flow in developing cladodes of Opuntia ficus-indica during sink to source transition. J. Expt. Bot. 48:675-682.

Wang, N., H. Zhang, and P.S. Nobel. 1998. Carbon flow and carbohydrate metabolism during sink-to-source transition for developing cladodes of Opuntia ficus-indica. J. Expt. Bot. 49:1835-1843. 